\title{
El pueblo crucificado, ensayo de soteriología histórica
}

\section{Ignacio Ellacuria \\ Centro de Reflexión Teológica, San Salvador, El Salvador.}

Para comprender lo que es el pueblo de Dios, importa mucho volver los ojos sobre la realidad que nos rodea, sobre la realidad de nuestro mundo tras cerca de dos mil años de existencia de la Iglesia, tras cerca de dos mil años desde que Jesús anunció el acercamiento del reino de Dios. Esta realidad no es sino la existencia de una gran parte de la humanidad literal e históricamente crucificada por opresiones naturales $y$, sobre todo, por opresiones históricas y personales. Y esa realidad despierta en el espíritu cristiano una pregunta insoslayable que abarca otras muchas: ¿qué significa para la historia de la salvación y en la historia de la salvación el hecho de esa realidad histórica que es la mayoría de la humanidad oprimida? ¿Se la puede considerar históricamente salvada, cuando sigue llevando sobre sí los pecados del mundo? ¿Se la puede considerar como salvadora del mundo precisamente por llevar sobre sí el pecado del mundo? ¿Qué relación tiene con la Iglesia como sacramento de salvación? Esa humanidad doliente ies algo esencial a la hora de reflexionar anbre lo que es el pueblo de Dios y sobre lo que es la Iglesia?

El enunciado de estas preguntas muestra la gravedad histórica y la importancia teológica de la cuestión. $Y$ es que en ella quedan envueltos muchos temas cristológicos y eclesiológicos; podría decirse que la cristología y la eclesiología enteras, en su carácter de soteriologia histórica. ¿Cómo se realiza la salvación de la humanidad desde Jesús? ¿Quién continúa en la historia esa función esencial, esa misión salvifica que el Padre encomendó al Hijo? La respuesta a estas preguntas puede dar carne histórica al pueblo de Dios, evitando asi la deshistorización de este concepto fundamental: 
evitando su falsa espiritualización e ideologización. Para ello es esencial la perspectiva de la soteriología histórica.

Por soteriología histórica se entiende aqui, ante todo, algo referente a la salvación, tal como ésta es propuesta en la revelación. Pero se acentuia su carácter histórico, y esto en un doble sentido: como realización de esa salvación en la historia única del hombre y como participación activa en ella de la humanidad, en nuestro caso de la humanidad oprimida. Qué humanidad históricamente oprimida sea la continuadora por antonomasia de la obra salvifica de Jesús y en qué medida lo sea, es algo que deberá descubrirse a lo largo de este ensayo. El hacerlo responde a una de las exigencias de la soteriologia histórica y aclara lo que ésta ha de ser. Ha de ser, por lo pronto, una soteriología que tenga como punto esencial de referencia la obra salvifica de Jesús; pero ha de ser, asimismo, una soteriologia que historice esa obra salvifica y la historice como continuación y seguimiento de Jesús y de su obra.

El análisis se hará tan solo desde un punto de vista: aquel que pone en unidad la figura de Jesús con la de la humanidad oprimida: ou pasión y muerte. Hay más puntos de vista, pero éste es esencial y merece un estudio por separado. En él confluye toda la vida y desde él se abre el futuro de la historia.

\section{La pasión de Jesús vista desde el pueblo crucificado y la} crucifixión del pueblo vista desde la muerte de Jesús

Se trata, ante todo, de una exigencia del método teológico tal como lo entiende la teologra latinoamericana: cualquier situación histórica debe verse desde su correspondiente clave en la revelación, pero la revelación debe enfocarse desde la historia a la que se dirige, aunque no cualquier momento histórico es igualmente válido para la rectitud del enfoque. El primer aspecto parece obvio desde la fe cristiana, por más que oculte una dificultad: la de encontrar la debida equivalencia, de modo que no se tome como clave de una situación lo que sería de otra. El segundo aspecto, en circularidad con el anterior, es menos obvio, sobre todo si se mantiene que la situación enriquece y actualiza la plenitud de la revelación y si se sostiene que no cualquier situación es la más apta para que la revelación dé en ella de sí su plenitud y su autenticidad.

En nuestro caso estamos ante dos polos decisivos, tanto por lo que toca a la revelación como por lo que toca a la situación. Su tratamiento conjunto aclara un problema fundamental en su doble vertiente: la historicidad de la pasión de Jesús y el carácter salvífico 
de la crucifixión del pueblo. Dicho de otro modo, aclara el carácter histórico de la salvación de Jesús y el carácter salvifico de la historia de la humanidad crucificada, una vez aceptado que en Jesús se da la salvación y que en la humanidad ha de darse la realización de esa salvación. Se da así un enriquecimiento tanto de lo que es la pasión de Jesús como de lo que es la crucifixión del pueblo $y$, consecuentemente, de lo que es Jesús y de lo que es el pueblo. Tal consideración, por otra parte, se enfrenta con dos dificultades muy graves: el dar sentido al aparente fracaso de la crucifixión de un pueblo, tras el anuncio definitivo de la salvación. Está en juego no sólo el fracaso de Dios frente al pecado de los hombres y la presencia del mal en la historia, sino también el sentido histórico de la inmensa mayor parte de la humanidad y, lo que es más grave, la tarea histórica de su salvación.

Es, por tanto, un enfoque preponderantemente soteriológico. No se pondrá el acento en lo que son Jesús y el pueblo, sino en lo que representan para la salvación de la humanidad. Ciertamente no es posible separar los aspectos llamados ontológicos de los llamados soteriológicos, pero sí es posible poner el acento en unos u otros. Y aquí se pondrá en los soteriológicos, advirtiendo que no se pretende reducir el ser y la misión de Jesús ni el ser y la misión del pueblo a la dimensión de la soteriología histórica, aunque ni el ser ni la misión quedan en ninguno de los dos casos debidamente iluminados si se prescinde de la consideración soteriológica.

Si esta advertencia es importante para evitar parcializaciones en la consideración de Jesús, que sólo son tales si se absolutizan, lo es también para evitar confusiones sobre el papel histórico que compete al pueblo oprimido en sus luchas históricas. Ese papel no se reduce al que resplandece en su comparación con la pasión y muerte de Jesús. Ni Jesús ni el pueblo crucificado, tal como aquí se le va a considerar, son la única salvación de la historia, aunque sin el uno y el otro la salvación de la historia no puede completarse ni siquiera en lo que tiene de salvación histórica. Lo primero es claro y admitido, si es que se atiende a la complejidad estructural de la historia humana; lo segundo es claro para el creyente, por lo menos en lo que toca al primer término, pero ha de mostrarse a los que no creen. Lo cual ha de hacerse de modo que su aporte a la salvación sea, por un lado, la verificación histórica de la salvación cristiana, pero, por otro, que no se convierta en una dulcificación y mistificación que impida la organización política popular y su aporte efectivo a la liberación histórica.

Proponer la salvación a partir de la crucifixión de Jesús y del 
pueblo supone el mismo escándalo y la misma locura, sobre todo si se quiere dar a la salvación un contenido verificable en la realidad histórica, donde "verificable" no quiere significar "agotable."

Desde una perspectiva cristiana, hoy ya no resulta escandaloso decir que la vida viene de la muerte histórica de Jesús, no obstante el escándalo que esto supuso para quienes vivieron esa muerte y la tuvieron que anunciar. $Y$, sin embargo, es menester recuperar el escándalo y la locura si no queremos desvirtuar la verdad histórica de la pasión de Jesús. Y esto en una triple dimensión: en la dimensión del propio Jesús, quien sólo paulatinamente pudo ir entendiendo cuál era el camino real del anuncio y la realización del reino de Dios; en la dimensión de quienes lo persiguieron a muerte, porque no podian aceptar que la salvación implicara determinadas posiciones históricas; finalmente, en la dimensión del escándalo eclesial, que hace rehuir a la Iglesia el paso por la pasión en el anuncio de la resurrección.

Pero sí resulta escandaloso el proponer a los necesitados y oprimidos como la salvación histórica del mundo. Resulta escandaloso a muchos creyentes, que ya no creen ver nada llamativo en el anuncio de que la muerte de Jesús trajo la vida al mundo, pero que no pueden aceptar teóricamente, y menos aún prácticamente que esa muerte que da vida pase hoy realmente por los oprimidos de la humanidad. Y resulta asimismo escandaloso a quienes buscan la liberación histórica de la humanidad. Es fácil ver a los oprimidos y necesitados como aquellos que requieren ser salvados y liberados, pero no lo es el verlos como salvadores y liberadores.

Es justo reconocer que hay movimientos históricos que ven en los oprimidos el sujeto radical de la salvación, sobre todo de la liberación histórica de los pueblos. Es conocido, por ejemplo, el famoso texto de Marx:

¿Dónde reside, pues, la posibilidad positiva de la emancipación alemana? Respuesta: en la formación de una clase con cadenas radicales, de una clase de la sociedad civil que no es una clase de la sociedad civil; de una clase que es la disolución de todas; de una esfera que posee un carácter universal debido a sus sufrimientos universales (durch ihre universellen Leiden) y que no reclama para sí ningún derecho especial, por que no se comete contra ella ningún daño especial, sino el daño puro y simple; que no puede invocar ya un título histórico, sino sólo un título humano; que no se encuentra en ninguna indole de antítesis unilateral con las consecuencias, sino en una antítesis total con 
las premisas del Estado alemán; de una esfera, por último, que no puede emanciparse (emanzipieren) sin emanciparse de todas las demás esferas de la sociedad y, al mismo tiempo, emanciparlas a todas ellas; que es, en una palabra, la perdida total (der vollige Verlust) del hombre y que, por lo tanto, solo puede ganarse a aí misma mediante la recuperación total (die vollige Wiedergewinnung) del hombre. Esta disolución (Auflosung) de la sociedad como clase especial (als ein besonderer Stand) es el proletariado.

El proletariado comienza a nacer, en Alemania, de resultas del movimiento industrial en ascenso. Pues lo que forme el pro. letariado no es la pobreza que nace naturalmente, sino la producida artificialmente; no las masas humanas mecánicamente agobiadas por el peso de la sociedad, sino las que nacen de la aguda disolución de ésta...

...es la disolución de hecho de ese orden universal...

Este texto, recogido con otros muchos en una edición de los escritos de Marx y Engels sobre la religión (Asmann, Reyes Mate), es buena prueba de que sí se ha pensado en los oprimidos como elementos de salvación, en este caso de revolución. Pero de él ha de decirse que tiene en sí mismo una profunda inspiración religiosa que se traduce en la terminología usada y que, por otra parte, no representa todo el pensamiento marrista -y menos su praxis histórica - sobre el problema en cuestion. Los ataques marxistas al Lumpenproletariat como freno a la revolución indican además un punto de vista que leído con poco rigor, puede dejar fuera del curso histórico a una gran parte de la humanidad crucificada. Es un punto en el que no podemos entrar ahora, pero que es menester no olvidar. $\mathrm{Si}$ el marxismo ha tenido la genialidad térica de dar al desposerdo por razones históricas un papel primordial en la recuperación total de la humanidad, en la construcción del hombre nuevo y de la tierra nueva, no por eso ha planteado en toda su universalidad ni en toda su intensidad, esto es, en toda su globalidad, su aporte a la salvación integral de la historia humana.

Resulte o no escandaloso el proponer la pasión y la crucifixión de Jesús y del pueblo como centrales para la salvación del hombre, la pasión de Jesús, precisamente por su propia inverosimilitud salvifica, ilumina la inverosimilitud salvifica de la crucifixión del pueblo, mientras que ésta evita una lectura ingenua o ideologizada de aquélla.

Por un lado, la resurrección de Jesús y sus efectos históricos son esperanza y futuro para quienes están todavía en los días de pasión. 
Ciertamente Jesús mantuvo la esperanza en el triunfo definitivo del reino de Dios, al que dedicó su vida y por el que murío. En Lucas 22, 15-18 (y su paralelo Mc 14, 25), a pesar de los retoques de la comunidad primitiva, es posible reconstruir una doble profecía de la muerte de Jesús: tras su muerte, Jesús celebrará de nuevo la pascua y organizará un banquete en el reino de Dios que ha de llegar necesariamente. Su muerte no impedirá la salvación futura y El mismo no será presa definitiva de la muerte. No quedarán, por tanto, separadas la irrupción del reino y la muerte violenta de Jesús (Schürmann). La muerte va inseparablemente unida en el caso de Jesús a la llegada escatológica e histórica del reino, por lo que la resurrección no significará tan sólo una comprobación o un consuelo, sino la seguridad de que ha de continuar su obra y de que EI sigue vivo para continuarla.

Pero esta esperanza de Jesús no fue tal que la pasión dejara de serlo hasta el punto del grito angustioso del abandono en la cruz. Su lucha por el reino, la certeza de que el reino de Dios triunfará definitivamente, no son óbice para que no "viera" la conexión entre sus días personales de lágrimas, entre el fracaso momentáneo del advenimiento del reino y la gloria del triunfo final. De ahí su ejemplaridad para los que aparecen más como los condenados de este mundo que como sus salvadores. Jesús en la condenación personal tuvo que aprender el camino de la salvación definitiva. Salvación, digámoslo una vez más, que consistía sustancialmente en el advenimiento del reino de Dios y no en una resurrección personal al margen de lo que fue su predicación terrena del reino.

Por el otro extremo, la pasión continuada del pueblo y lo que va con ella, el reino histórico del pecado - como contrapuesto al reino de Dios-, no permiten hacer una lectura ahistórica de la muerte y resurrección de Jesús. El defecto fundamental de tal lectura consistiría en desterrar de la historia el reino de Dios para relegarlo a una etapa más allá de la historia de modo que en ésta ya no tuviera sentido continuar la vida y la misión del Jesús anunciador del reino. Esto sería una traición a la vida y la muerte de Jesús, toda ella dedicada no a sí mismo, sino al reino. Por otro lado, la identificación del reino con la resurrección de Jesús dejaría sin cumplimiento el mensaje de Jesús, que anunciaba persecuciones y muerte a los que fueran a continuar su obra. Cuando Pablo recuerda lo que falta todavía a la pasión de Cristo, está desechando una resurrección ahistórica que hace caso omiso de lo que está ocurriendo en la tierra. Es precisamente el reino del pecado que sigue crucificando a la mayoría de la humanidad el que obliga a la 
historización de la muerte de Jesús como pascua histórica del reino de Dios.

\section{Importancia teológica de la cruz en la historia de galva- ción}

El enfoque ascético y moralista de la cruz cristiana ha desvirtuado la importancia histórica de la cruz y ha suscitado un rechazo de todo lo que tenga que ver con ella. Tal rechazo está plenamente justificado si es que no responde a la salida inmadura de quien se libera de sus fantasmas emocionales. La renovacion del misterio de la cruz poco tiene que ver con la represión gratuita, que sitúa la cruz donde uno quiere y no donde está puesta, como si el propio Jesús hubiera buscado para si la muerte en cruz y no el anuncio del reino.

Más peligroso resulta el intento de evadir la historia de la cruz en las teologias de la creación y de la resurrección que hacen de ella, en el mejor de los casos, un incidente o un misterio puntual que proyecta místicamente su efectividad sobre las relaciones del hombre con Dios.

La consideración "naturalista" de la creación, por muy creyente que se confiese, desconoce la novedad del Dios cristiano que se revela en una historia de la salvación. Ignora incluso que Israel no llegó a la idea del Dios creador por reflexiones racionales sobre el curso de la naturaleza, sino por reflexión teológica sobre lo acaecido al pueblo elegido. Von Rad ha mostrado claramente que es en las luchas políticas del Exodo donde Israel he tomado conciencia de que Yahvé es su salvador y redentor; que esta salvación ha sido concebida como la creación y puesta en marcha de un pueblo y que la fe en Dios creador del mundo es un hallazgo posterior, una vez que la experiencia histórica del pueblo de Israel en el fracaso del exilio lo va orientando hacia una conciencia universalista, que exige un Dios creador universal de todos los hombres. Una fe al margen de la historia, una fe al margen de los acontecimientos históricos tanto en la vida de Jesús como en la vida de la humanidad, no es, en consecuencia, una fe cristiana. Será, en el mejor de los casos, una especie de teísmo más o menos corregido.

Pero tampoco es cristiana una postura que se apoye exclusivamente en la vivencia creyente del resucitado y olvide las rarces históricas de la resurrección. La tentación es antigua y, con toda probabilidad, ocurrió ya en las comunidades primitivas, lo cual las obliǵ́ muy pronto a subrayar la continuidad del resucitado con el 
crucificado. Si asi no se hace, se vive en la falsa suposición de que ya ha terminado la lucha contra el pecado y contra la muerte tras el triunfo de la resurrección. De nuevo se reducirá asf el reino de Dios a algo futuro que, por su proximidad temporal, ya no necesita de la contribución humana o que, por su lejanía, reduce el reino a la resurrección de los muertos. Y es que si la vida del resucitado es la misma que la de Jesús de Nazaret, quien fue crucificado por nosotros, la vida inmortal del resucitado es el futuro de salvación sólo bajo la condición de abandonarse a la obediencia del crucificado, capaz de vencer el pecado (Pannenberg).

La conexión inmediata de creación y resurrección es, en consecuencia, falsa desde un punto de vista cristiano, cualquiera que sea el modo de entender la "imagen y semejanza" original, el proceso histórico de muerte y resurrección. $Y$ todo proceso histórico es una creación de futuro y no meramente una renovación del pasado. No se restaura al hombre caído, sino que se construye un hombre nuevo; pero se lo construye en la resurrección de quien ha luchado hasta la muerte contra el pecado. Dicho de otro modo: la esperanza escatológica se expresa a la par como reino de Dios y como resurrección de los muertos, lo cual significa para Pannenberg -que no es precisamente un teólogo de la liberación- que el reino de Dios no es posible como una comunidad de los hombres en paz perfecta y total justicia sin un cambio radical de las condiciones naturales presentes de la existencia humana, un cambio que se designa con la resurrección de los muertos. Expresa también que van juntos el destino individual y el destino político del hombre.

De ahi que la resurrección remita a la crucifixión: resucita el crucificado y resucita por haber sido crucificado; ya que le fue arrebatada la vida por el anuncio del reino de Dios, le es devuelta una vida nueva como cumplimiento de ese reino. La resurrección remite, así, a la pasión y la pasión a la vida de Jesús como anunciador del reino. Es sabido que tal es el curso seguido en la construcción de los evangelios: la necesidad de historizar la vivencia del resucitado lleva a la consideración histórica de la pasión, la cual ocupa un lugar tan desproporcionadamente amplio en los relatos evangélicos y exige una justificación histórica en la narración de la vida de Jesús. Como quiera que sea, todo el conjunto intenta valorar teológicamente dos hechos que responden a una misma realidad: el hecho del fracaso de Jesús en el escándalo de su muerte y el hecho de la persecución que sufren pronto las comunidades primitivas.

No se trata, por tanto, de un masoquismo expiatorio de índole 
espiritualista, sino del descubrimiento de una realidad historica. No se trata, en consecuencia, de luto y mortificación, sino de ruptura y compromiso. La muerte de Jesús pone en claro por qué el anuncio efectivo de la salvación choce con la resistencia del mundo, por qué el reino de Dios combate con el reino del pecado. Y esto aparece tanto en la muerte del profeta, del enviado de Dios, como en la muerte y el destrozo de la humanidad por quienes se hacen dioses dominadores de ella. Si una consideración espiritualista de la pasión lleva a la evasión del compromiso histórico que conduce a la persecución y a la muerte, un compromiso histórico con el pueblo crucificado obliga a volver la mirada sobre el sentido teológico de ese compromiso y a retrotraerse asf a la pasión redentora de Jesús. La consideración histórica de la muerte de Jesús ayuda a la consideración teológica de la muerte del pueblo oprimido, y ésta remite a aquélla.

3. La muerte de Jesús y la crucifixión del pueblo son hechos históricos y resultado de acciones históricas

a) Puede admitirse que la muerte de Jesús y la crucifixión del pueblo son necesarias, pero sólo si se habla de una necesidad histórica y no de una necesidad meramente natural. Precisamente su carácter de necesidad histórica aclara la realidad profunda de lo que ocurre en la historia, a la par que abre un campo para su transformación, lo cual no ocurriria si se tratase de una necesidad meramente natural.

La propia Escritura, cuando intenta justificar la pasión de Jesús, señala esta necesidad y aun la fórmula a modo de principio: "ino tenía que padecer (edei pathein) todo eso el Mesías para entrar en su gloria?" (Lc 24, 36). Pero este "tener que" padecer "para" alcanzar su plenitud es un "tener que" histórico. Histórico, no porque así lo habian anunciado los profetas, sino porque los profetas prefiguraron el suceso en lo que a ellos mismos les acaeció. Esa necesidad se funda, a través de lo que les ocurrió a los profetas, en la oposición entre el anuncio del reino y la vertificación histórica del pecado. La resistencia a los poderes opresores y la lucha por la liberación histórica les trajo persecución y muerte, pero esa resistencia y esa lucha no eran sino la consecuencia histórica de una vida que responde a la palabra de Dios. Tan larga experiencia, recogida expresamente por Jesús, lleva a la conclusión que en nuestro mundo histórico es necesario el paso por la persecución y la muerte para llegar a la gloria de Dios. Y la razón no puede ser más clara: si el 
reino de Dios y el reino del pecado son dos realidades opuestas y ambas tienen como protagonista al hombre de carne $y$ hueso, quienes ostentan el poder de dominación opresora no podrán menos de ejercitarlo contra quienes sólo tienen el poder de su palabra y de su vida, ofrecidas por la salvación de muchos.

No se trata, por tanto, de la imagen biológica de la semilla que muere para dar fruto, ni de una ley dialéctica que exige el paso por la muerte para llegar a una vida nueva. Ciertamente hay textos escrituristicos que hablan de la necesidad de la muerte de la semilla, pero esos textos indican la necesidad y el movimiento dialéctico de esa necesidad, pero no la "naturalizan." Naturalizarla implicarfa, por un lado, quitar responsabilidad a quienes matan a los profetas y a quienes crucifican a la humanidad, y echar así un velo a lo que el mal histórico tiene de pecado; e implicarí, por otro, que la nueva vida puede surgir sin la actividad de los hombres, que no necesitarian ni convertirse en su interior ni rebelarse contra su exterior. Es verdad que las imágenes "biológicas" del reino subrayan a veces cómo el crecimiento es cosa de Dios, pero de ahí no puede concluirse que los hombres deben abandonar el cuidado del campo de la historia.

La necesidad histórica, en cambio, obliga a subrayar las causas necesitantes de lo que ocurre. La fundamental, desde un punto de vista teológico, está expresada innumerables veces en la Escritura: el paso por la muerte a la gloria es necesario sólo en el supuesto del pecado, un pecado que se apodera del corazón del hombre; pero, sobre todo, un pecado histórico que reina sobre el mundo y sobre los pueblos colectivamente. Hay un "pecado teologal y colectivo" (Moingt) al que se refiere el anuncio de la muerte de Cristo por nuestros pecados, la cual no dice relación directa a nuestros pecados individuales y éticos; una "realidad colectiva" que fundamenta y posibilita los pecados individuales. Es este pecado teologal y colectivo el que destruye la historia y obstaculiza el futuro que Dios querría para ella; este pecado colectivo es el que hace reinar la muerte sobre el mundo, y por ello tenemos necesidad de ser liberados de nuestra obra colectiva de muerte para formar de nuevo el pueblo de Dios. Y es el propio Moingt el que llega a decir que la redención será idénticamente "la liberación política del pueblo y su conversión a Dios."

Esta necesidad histórica tiene carácter distinto de la gloria: es necesario pasar por la muerte a la gloria, pero no es necesario que la gloria siga a la muerte. Consecuentemente, una es la actitud en la lucha contra el pecado y otra en la recepción de la vida. En ambos 
casos hay una cierta exterioridad en relación con el hombre individual: el mal del mundo, el pecado del mundo no es sin más, la suma de determinadas acciones individuales, ni éstas son ajenas a ese pecado que las domina; igualmente el perdon del mundo, la transformación del mundo, es algo que inicialmente recibe el hombre para después poder aportar su contribución. Pero la exterioridad es distinta en el caso del mal y del bien, del pecado y de la gracia: mientras en el caso del pecado es obra del hombre, en el caso de la gracia es obra de Dios, aunque sea una obra que opera en el hombre y que opera a través de él, quedando aś excluida toda pasividad. Aunque Dios dé el crecimiento no se excluye, sino que se precisa la acción laborante del hombre, ante todo en la destrucción de la objetividad del pecado $y$, después, en la construcción de la objetivación de la gracia. De lo contrario, la necesidad no tendria carácter histórico, sino que sería puramente natural y el hombre sería o la negación absoluta de Dios o un mero ejecutor de unos presuntos planes divinos.

El carácter "necesario" de la muerte de Jesús no es visto sino tras el hecho ocurrido. $\mathrm{Ni}$ sus discípulos ni El mismo vieron en un principio, ni siquiera con la consideración de las Escrituras, que el anuncio y el triunfo del reino debieran pasar por la muerte. Cuando ocurrio, las mentes sorprendidas de los creyentes encontraron en los designios de Dios, manifestados en las palabras y en los hechos de las Escrituras - Moisés y los profetas-, los signos de la voluntad divina que hacían "necesaria" la muerte.

Esta "necesidad" no se funda en consideraciones expiatorias y sacrificiales. Incluso cuando se recurre al segundo Isaias para explicar, mediante el siervo de Yahvé, el significado de la muerte de Jesús, el hilo del discurso no es "pecado-ofensa-víctima-expiaciónperdón." Este esquema, que puede tener alguna validez para determinadas mentalidades y que expresa en sí mismo algunos puntos válidos, puede convertirse en evasión de lo que ha de hacerse históricamente para quitar el pecado del mundo. En momentos en que se oprimía a las conciencias o las conciencias se sentían oprimidas por un cristianismo centrado sobre la idea del pecado, de la culpabilidad y de la condenación eterna, era imprescindible el esquema del perdón, en el que un Dios ofendido perdonaba la culpa y anulaba la condena. Pero este esquema, con sus puntos válidos, no subraya ni la objetivación colectiva del pecado ni la acción humana -destructora de la injusticia y constructora del amor-, que son "necesarias" históricamente. Una nueva teología del pecado debe sobrepasar los esquemas expiatorios, pero no debe permitir que se 
olvide la existencia del pecado. Olvidarlo serfa, entre otras cosas, dejar el campo libre a las fuerzas de opresión masivamente reinantes en nuestro mundo y también descuidar el campo de la conversión personal.

b) Por ello, subrayar el carácter histórico de la muerte de Jesús es fundamental para la cristología y para la soteriología histórica, que como tal cobraría un sentido nuevo.

El carácter histórico de la muerte de Jesús implica, por lo pronto, que su muerte ocurrió por razones históricas. Es un punto que con razón subrayan cada día más las nuevas cristologías. Jesús muere -es matado, como insisten tanto los cuatro evangelios como los Hechos- por la vida histórica que llevó, vida de hechos y de palabras que no podía ser tolerada por los representantes y detentadores de la situación religiosa, socio-económica y política. Que se lo considere blasfemo, destructor del orden religioso tradicional, perturbador de la estructura social, agitador político, etc., no es sino reconocer desde los más distintos ángulos que la acción, la palabra y la persona misma de Jesús en el anuncio del reino eran de tal modo beligerantes y contrarias al orden establecido y a las instituciones fundamentales, que debían ser castigadas con la muerte. La deshistorización de este hecho radical lleva a enfoques místicos del problema; y esto no por profundización, sino por evasión. El "muerto por nuestros pecados" no puede despacharse fácilmente por el camino de la victima expiatoria que deja intacto el curso historico.

Implica, asimismo, que Jesús emprendi6 una determinada marcha histórica no porque llevase a la muerte ni porque El buscase una muerte redentora, sino porque así lo exigia el anuncio real del reino de Dios. Ya sea que subraye el carácter soteriológico de la muerte de Jesús, como lo hace Lucas, en ninguno de los dos casos puede olvidarse que el Jesús histórico no buscó de por af ni la muerte ni la resurrección, sino el anuncio hasta la muerte del reino de Dios, que trajo consigo la resurrección. Jesús vio que su acción lo llevaba a un enfrentamiento mortal con quienes le podían quitar su vida, y es absolutamente impensable que no viera la probabilidad real de su muerte, e incluso su cercanía, junto con las causas de ella y de su probabilidad. Más aún, vio mejor y antes el valor salvífico en un sentido amplio - de su persona y de su vida que el valor salvífico de su muerte. En efecto, no empieza por centrar su acción en la espera de la muerte, sino en el anuncio del reino; y aun cuando ve la muerte como posibilidad real, no ceja en dicho anuncio ni cede en su choque con el poder. No son conciliables su vida y las exigencias a 
los discípulos con el paso de todo el valor salvífico a la muerte: no puede decirse que haya en El un paulatino deslizamiento de la vida a la muerte como centro de su mensaje, pues aun en los numerosos textos del seguimiento difícil y contradictorio, el acento está en la continuidad de la vida con la muerte y no en la ruptura de la muerte frente al camino de salvación que representa su vida.

La salvación, entonces, no puede imputarse exclusivamente a los frutos místicos de la muerte de Jesús, separándola de lo que es un comportamiento real y comprobable. No se trata meramente de una aceptación pasiva y obediente de un destino natural, y menos aún de un destino impuesto por el Padre. Se trata, al menos en un primer plano, de una acción que lleva a la vida a través de la muerte, de modo que no es posible separar lo salvifico y lo histórico en el caso de Jesús. En consecuencia, la muerte de Jesús no es el final del sentido de su vida, sino el final del esquema que debe ser reproducido y seguido en nuevas vidas con la esperanza de la resurrección y con el sello de la exaltación. La muerte de Jesús es el sentido final de su vida sólo porque la muerte a la que lo llevó su vida muestra cuál era a la par el sentido histórico y el sentido teológico de su vida; es entonces su vida la que da el sentido último de su muerte, y sólo en consecuencia es la muerte, que ya ha recibido el sentido inicial de la vida, sentido de la vida. De ahí que sus seguidores no deben poner primariamente el centro de su atención en lo que es la muerte como sacrificio, sino en lo que es la vida de Jesús, que sólo será realmente la de $\mathrm{El}$ si lleva a las mismas consecuencias a las que llevó la suya.

La soteriologia histórica lo que hace es buscar dónde y cómo se realiź́ la acción salvífica de Jesús, para proseguirla en la historia. Es cierto que, en un sentido, la vida y muerte de Jesús se han dado una vez por todas, pues en ellas no se trata de algo puramente fáctico que tuviera el mismo valor que el de cualquier otra muerte tenida en iguales circunstancias, sino de algo que supone la presencia definitiva de Dios entre los hombres. Pero esa vida y esa muerte continúan en la tierra y no sólo en el cielo: la unicidad de Jesús no está en su separación de la humanidad, sino en el carácter definitivo de su persona y en la omnipresencia salvífica que le compete. Toda la insistencia en su carácter de cabeza respecto de un cuerpo, así como en el envio de su Espíritu por el que se continuará su obra, apuntan a este corrimiento histórico de su vida terrenal. La continuidad no es puramente mística y sacramental, como no fue puramente mística y sacramental su acción en la tierra; dicho de otro modo, no es el culto, ni siquiera la celebración de la eucaristía, 
el totum de la presencia y de la continuidad de Jesús, sino que se requiere la continuación histórica que siga realizendo lo que El realizo y como El lo realizo. Debe aceptarse una dimension transhistórica en la acción de Jesús, como debe reconocérsela en su biografia personal, pero esa dimensión transhistórica sólo será real si es efectivamente transhistórica, esto es, si atraviesa la historia. Por ello hay que preguntarse quién sigue realizando en la historia lo que fue su vida y su muerte.

c) Podemos acercarnos a la respuesta considerando que hay un pueblo crucificado, cuya crucifixión es resultado de acciones históricas. Tal vez esta constatación no baste para mostrar que este pueblo crucificado es la continuación histórica de la vida y la muerte de Jesús. Pero antes de profundizar en otros aspectos que muestren el que sea asi, conviene arrancar del mismo punto desde el cual arranca el valor salvifico de la vida y la muerte de Jesús.

Se entiende aquí por pueblo crucificado aquella colectividad que, siendo la mayoría de la humanidad, debe su situación de crucifixión a un ordenamiento social promovido y sostenido por una minoria que ejerce su dominio en función de un conjunto de factores, los cuales, como tal conjunto y dada su concreta efectividad histórica, deben estimarse como pecado. No se trata, por tanto, de una consideración puramente individual de todo aquel que sufre incluso por acciones injustas de los otros o porque es sacrificado como luchador contra la injusticia reinante; aunque la consideración colectiva del pueblo crucificado no excluye la consideración individualizada, subsume ésta en aquélla, precisamente porque es el lugar histórico de su realización. No se trata tampoco de una consideración puramente natural de los que sufren por desgracias naturales; aunque también los males naturales entran, derivadamente, en cuanto se hacen presentes en un orden historico determinado.

Considerar a una colectividad como sujeto de la salvación no álo no es ajeno a la Escritura, sino que es en ella un sentido originario. Por ejemplo, un individuo sólo puede constituirse en siervo de Yahvé en tanto que es miembro del pueblo de Israel (J. Jeremias), porque la salvación está ofrecida primariamente al pueblo y en el pueblo. La experiencia conjunta de que la rafz de los pecados individuales está en una presencia del pecado supraindividual y de que la vida de cada uno está configurada por lo que es la vida del pueblo en el que se vive, hace connatural la vivencia de que en esta dimensión de colectividad se juega primariamente tanto la salvación como la perdición. La insistencia moderna en individualizar la existencia 
humana sólo será realista si no implica un desconocimiento de su dimensión social, cosa que no ocurre en los paroxismos individualistas e idealistas tan propios de la cultura occidental 0 , por lo menos de las élites de esa cultura. Todo lo que esta concepción trae de egorsmo y de irresponsabilidad social no deja de ser contraprueba de la falsedad de esa exageración. No se necesita negar la dimensión colectiva y estructural para dar campo a un desartollo pleno de la persona.

Pero si no se trata de una definición teológicamente arbitraria, mucho menos se trata de una definición realmente arbitraria. Se trata, por lo pronto, de una constatación histórica enfocada soteriológicamente. Quien está preocupado creyentemente por el pecado y la salvación del mundo, no puede menos de hacer esa constatación histórica de la humanidad crucificada en esa forma concreta de pueblo crucificado; igualmente, quien considere creyentemente la existencia lacerante de ese pueblo crucificado, tiene que preguntarse por lo que tiene de pecado y de necesidad de salvación. Frente a esta realidad tan masiva y tan grave, la consideración segregada de los casos particulares de quienes no pertenecen al pueblo crucificado pasa a un segundo lugar, aunque deba repetirse de nuevo que la consideración universalista y estructural no tiene por qué anular la consideración individualista y psicológica, sino tan sólo darle su marco real de referencia. Lo que shade la fe cristiana a la constatación histórica del pueblo oprimido es la sospecha de si, además de ser el destinatario principal del esfuerzo salvífico, no será también en su situación crucificada principio de salvación para el mundo entero.

No es éste el lugar para caracterizar la magnitud cuantitativa y cualitativa de lo que es la opresión histórica de la actual mayoría de la humanidad, ni tampoco para hacer el estudio pormenorizado de sus causas. Aunque es uno de los hechos fundamentales de los que debe partir la reflexión teológica y aunque haya sido escandalosamente olvidado por quienes teorizan desde el mundo geográfico de los opresores, es de tal evidencia y amplitud que no necesita explanación. Lo que sí necesita es ser vivido experiencialmente.

Pues bien, aunque no pueden negarse componentes "naturales" de la actual situación historica de injusticia que define nuestro mundo, tampoco puede desconocerse lo que tiene de resultado de acciones históricas. Como en el caso de Jesús, no puede hablarse de una necesidad puramente natural: la opresión del pueblo crucificado viene de una necesidad historica: la necesidad de que muchos sufran 
para que unos pocos gocen, de que muchos sean desposerdos para que unos pocos posean; la represión de sus vanguardias, por otra parte, sucede según el mismo esquema, aunque con distintos sentidos, que en el caso de Jesús.

Este planteamiento general debe, sin duda, historizarse. No siempre y en todo lugar ha ocurrido y ocurre de la misma forma ni por las mismas causas, pues el esquema general de la opresión del hombre por el hombre adquiere colectiva e individualmente formas muy distintas. Pero en la actualidad universal de nuestros días, la opresión tiene unas características historicas globales que no pueden ignorarse y de las que son responsables activos u omisivos cuantos no se ponen al lado de la liberación.

Asimismo, dentro de este planteamiento colectivo y generalizante deben hacerse análisis más particularizantes. Aunque se mantenga el esquema universal que se crucifica al otro para vivir uno mismo, deben examinarse los subsistemas de crucifixión que hay en cada uno de los dos grupos: el grupo de los opresores y el grupo de los oprimidos. Muchas veces se ha insistido en la gravedad y en la multiplicidad de las formas en que, dentro del mundo de los oprimidos, hay quienes se ponen al servicio de los opresores o desatan sus propios instintos de dominación. Es un hecho real que obliga a superar las simplificaciones esquemáticas tanto de las causas de la opresión como de sus formas, para no caer en una división maniqueísta del mundo, que pondría a un lado todo lo bueno y al otro lado lo malo. Precisamente una consideración estructural del problema evita el caer en el error de admitir como buenos a todos los individuos de un campo y como malos a los del contrario, dejando así de lado el problema de la transformación personal. La huida de la muerte propia en un permanente mirar por sí sin aceptar que la vida se gana cuando se la entrega a los otros, es sin duda una tentación intrínseca y permanente del hombre que queda modulada, pero no anulada por la realidad histórico-estructural.

El enfoque de la muerte de Jesús y de la crucifixión del pueblo, la remisión de la una a la otra, hace que ambas aparezcan a una nueva luz. La crucifixión del pueblo evita el peligro de mistificar la muerte de Jesús, y la muerte de Jesús evita el peligro de magnificar salvificamente el mero hecho de la crucifixión del pueblo, como si el hecho bruto de ser crucificado aportara sin más la resurrección y la vida. Hay que iluminar esta crucifixión desde lo que fue la muerte de Jesús para ver su alcance salvifico y el modo cristiano de esa salvación. Hay que examinar para ello los principios de vida que se 
entremezclan con los principios de muerte; aunque la presencia del pecado y de la muerte es masiva en la historia del hombre, también es importantísima y palpable la presencia de la gracia y de la vida. Si no se puede olvidar un aspecto, tampoco el otro. Más eún, la salvación solo podrá entenderse como un triunfo de la vida sobre la muerte, un triunfo que ya está preanunciado en la resurrección de Jesús, pero que debe ser procesualmente ganado siguiendo sus propios pasos, conforme al sentido que tuvieron en El.

\section{La muerte de Jesús y la crucifixión del pueblo vistag deade el Siervo de Yahvé}

Una de las pistas en las que se fijo la comunidad cristiana primitiva para comprender y dar su valor adecuado a la muerte de Jesús, fue la figura del siervo de Yahvé tal como la describió el deutero-Isaías. Este hecho permite acudir de nuevo al siervo sufriente para ver desde él lo que fue, en uno de sus aspectos, la muerte de Jesús y, sobre todo, lo que es también, en uno de sus aspectos, la crucifixión del pueblo.

Tendrá así tres partes esta sección: en la primera se recogerán algunas de las caracteristicas del siervo tal como las propone el deutero-Isaías; en la segunda se contrastarán esas características con lo que fue la vida y muerte de Jesús; finalmente, en la tercera parte, con lo que son o deben ser las características del pueblo oprimido si ha de ser el continuador de la obra redentora de Jesús. Las dos primeras partes estarán orientadas a la tercera. Así, si no llegara a probarse que el pueblo oprimido es la continuación histórica de la crucifixión y del crucificado, se mostrará al menos qué camino debe seguirse para configurar su muerte con la de Cristo, habida cuenta, sin embargo, de la distinta realidad que son y de la diferente función que les compete.

\subsection{Características del siervo de Yahvé}

Haremos el análisis del siervo doliente de Yahvé desde la perspectiva del pueblo crucificado. Toda lectura se hace desde una situación más que desde una precomprensión, la cual esté determinada de algún modo por la situación. Los que pretenden que es posible una lectura neutra de un texto de la Escritura cometen un doble error: un error epistemológico, al creer posible una lectura no condicionada; y un error teológico, por cuanto desdeñan el lugar más apto de lectura, que será siempre el destinatario principal al que va dirigido el texto: este destinatario es en cada momento histórico un 
destinatario distinto, y aquí trabajamos con la hipotesis de que en nuestro momento es el pueblo crucificado, hipotesis que será confirmada, si es que el pueblo crucificado queda iluminado por lo que dice el texto y si el texto queda enriquecido y actualizado por la realidad de este destinatario histórico. No es éste lugar para mostrar la justificación epistemológica y teológica de este procedimiento metodológico, que no excluye la utilización más cuidadosa de los análisis exegéticos, sino que tan sólo los subordina; baste con explicitarlo para no llevarse a engaño.

Se prescindirá en el análisis de si el "siervo" es un personaje colectivo o individual, si es un rey o un profeta, etc. Nada de esto es relevante para nuestro propósito, pues lo que se intenta aquí formalmente es ver lo que dice el texto al pueblo oprimido, lo que habla el texto a este destinatario histórico. No se hará, claro está, un tratamiento exhaustivo, sino un apuntamiento de las líneas fundamentales.

La teología del siervo presupone que el encuentro de Yahvé ocurre en la historia, que se constituye asf en el lugar de su proximidad y en el lugar de la respuesta y la responsabilidad del pueblo (J. Jeremias). La unidad entre lo que ocurre en la historia y lo que Dios quiere manifestar y comunicar a los hombres es, en el texto del deutero-Isaías, indisoluble; recordemos las referencias a la humillación de Babilonia y al triunfo de Ciro como pruebas contundentes. En este contexto han de leerse los cuatro cantos del siervo doliente.

El primer canto (Is 42, 1-7) habla de la elección del siervo, que es un elegido, un preferido de Yahvé, sobre el que éste ha puesto su espiritu. La finalidad de esta elección es manifestada paladinamente: "para que traiga el derecho a las naciones." $Y$ no contento con esta formulación tan explícita, insiste y amplifica: "promoverá fielmente el derecho, / no vacilará ni se quebrara / hasta implantar el derecho en la tierra, / y sus leyes que esperan las islas." Se trata, por tanto, de una implantación objetiva del derecho, de la justicia ante todo, en el sentido real de hacer justicia a un pueblo oprimido, de crear unas leyes en las cuales predomine la justicia y no los intereses de los poderosos; aunque también se tiene en cuenta la necesidad de que se interiorice el amor a la justicia, esto es, de que se haga un hombre nuevo que viva de verdad el derecho y la justicia. Hay asimismo una mirada universal sobre las naciones y las islas, esto es, no se queda en un ámbito puramente judaico. Y es una respuesta de Dios a lo que "esperan" los pueblos sin derecho, una respuesta que se implantará por el siervo, que no vacilará ni se quebrará en su misión. 
La elección es por parte de Dios. Por muy política que parezca la misión en su primer paso (no se habla de que se restaurará el culto, de que se convertirán los pecadores, etc., sino de la implantación del derecho), es lo que Dios quiere, el Dios "que creó y desplegó el cielo," el que consolido la tierra. Pues bien, este Dios es el que ha elegido al siervo para hacer la justicia: "Yo, el Señor, te he llamado para la justicia, / te he cogido de la mano, / te he formado y te he hecho / alianza de un pueblo, luz de las naciones" $(42,6)$. Y se vuelve a repetir, explicándolo, lo que es hacer justicia: "para que abras los ojos de los ciegos, / saques a los cautivos de la prisión / y de la mazmorra a los que habitan las tinieblas" $(42,7)$. Y eso lo dice el Señor y ése es su nombre, es decir, en eso se expresa su ser para los hombres, en ese su anuncio de futuro frente a lo que ha estado sucediendo.

El segundo cántico subraya el carácter de elección por parte de Dios: ha elegido a quien desprecian los poderosos, a quien parece no tener fuerzas para hacer reinar la justicia sobre el mundo y que, sin embargo, tiene el respaldo de Dios; "en realidad mi derecho lo defendía el Senor, / mi salario lo tenía mi Dios." "Así dice el Señor, redentor y Santo de Israel, / al despreciado, al aborrecido de las naciones, / al esclavo de los tiranos: / Te verán los reyes, y se alzarán; los príncipes, y se postrarán; / porque el Señor es fiel, porque el Santo de Israel te ha elegido" (49, 4 y 7$)$. La elección es para construir una tierra nueva y un pueblo nuevo: "para restaurar el país, para repartir heredades desoladas" $(49,8)$. Saldrá el pueblo de su estado de pobreza, de opresión y oscuridad a un nuevo estado de abundancia, de libertad y de luz. Y la razón de la intervención divina a través de su siervo es clara: "Porque el Señor consuela a su pueblo / y se compadece de los desamparados" $(49,13)$. Esta idea de que Dios está al lado del oprimido y contra el opresor es fundamental en el texto $y$ se refiere $a$ un pueblo entero $y$ no solamente a individuos particulares: "Haré a tus opresores comerse su propia carne, / se embriagarán de su sangre como de vino; / y sabrá todo el mundo que yo soy el Señor, tu salvador, / que tu redentor es el héroe de Jacob" $(49,26)$.

El tercer cántico da un paso nuevo al resaltar la importancia que pueden tener los sufrimientos en la marcha liberadora del pueblo. La larga experiencia del abatimiento puede llevar a la desconfianza, pero el Señor va a respaldar ese sufrimiento y va a terminar dando la victoria a quien aparentemente está derrotado: "El Señor me ayuda, por eso no sentía los ultrajes; / por eso endurecí el rostro como pedernal, / sabiendo que no quedaría defraudado" $(50,7)$. Una 
gran esperanza se abre en el futuro de los afligidos y perseguidos; su dolor no es en vano, sino que Dios está tras él. Una esperanza que tocarán con sus manos y que transformará por completo sus vidas: "los rescatados del Sefíor volverán: vendrán a Sión con cénticos, en sus cabezas alegría perpetua, / siguiéndolos gozo y alegría, pena y aflicción se alejarán" $(51,11)$.

Pero es en el cuarto cántico donde se desarrolla más el tema de la pasión y gloria del siervo. Ante todo, la contraposición centra lo que es la situación del siervo y su capacidad real de salvación: "Miren, mi siervo tendrá éxito, subirá y crecerá mucho. / Como muchos se espantaron de él, porque desfigurado no parecia hombre / ni tenía aspecto humano, / así asombrará a muchos pueblos; / ante él los reyes cerrarán la boca, / al ver algo inenarrable y contemplar algo inaudito" (52, 13-15). Es aqú donde la descripción de la persecución del siervo en su misión de implentar el derecho reviste caracteres muy similares a los que sufre hoy el pueblo oprimido:

Creció en su presencia como brote, como raíz en tierra árida, sin figura, sin belleza.

Lo vimos sin aspecto atrayente, despreciado y evitado de los hombres, como un hombre de dolores acostumbrado a sufrimientos ante el cual se ocultan los rostros, despreciado y desestimado. El soportó nuestros sufrimientos y aguantó nuestros dolores: nosotros lo estimamos leproso, herido de Dios y humillado; triturado por nuestros crímenes.

Nuestro castigo saludable cayo sobre él, sus cicatrices nos curaron.

Todos errábamos como ovejas, cada uno siguiendo su camino, y el Señor cargó sobre él todos nuestros crímenes.

Maltratado, se humillaba y no abría la boca...

Sin defensa, sin justicia, se lo llevaron, ¿quién meditó en su destino?

Lo arrancaron de la tierra de los vivos, por los pecados de mi pueblo lo hirieron.

Le dieron sepultura con los malvados y una tumba con los malhechores, aunque no había cometido crímenes ni hubo engaño en su boca. 
El Señor quiso triturarlo con el sufrimiento y entregar su vida como expiación: verá su descendencia, prolongará sus años, lo que el Señor quiere prosperará por su mano.

Por los trabajos de su alma verá la luz, el justo se saciará de conocimiento.

Mi siervo justificará a muchos porque cargó con los crimenes de ellos.

Le dará una multitud como parte, y tendrá como despojo una muchedumbre.

Porque expuso su vida a la muerte y fue contado entre los pecadores, él cargo con el pecado de muchos e intercedi6 por los pecedores $(53,2-12)$.

Este texto, fundamental en cualquier teología de la salvación, en cualquier soteriologia, admite diversas lecturas, porque puede iluminar problemas distintos. En el que nos ocupa ahora, no puede desconocerse hasta qué punto se acomoda en la descripción a lo que ocurre con el pueblo crucificado. Si una lectura ya tradicional ha visto preanunciada en él la figura de la pasión de Jesús, no hay por qué cerrar los ojos a lo que tiene de realmente descriptivo -al margen de toda acomodación- de lo que es hoy una inmense mayor parte de la humanidad. Desde esta perspectiva pueden subrayarse algunos momentos histórico-teológicos de este cántico impresionante.

En primer lugar, se trata de una figura destrozada por la intervención historica de los hombres: es un hombre de dolores, acostumbrado al sufrimiento, que es llevado a la muerte sin defensa y sin justicia; desestimado y despreciado por todos; alguien en quien no se ve mérito alguno.

En segundo lugar, no sólo no se lo considera como posible salvador del mundo sino, todo lo contrario, como leproso, como condenado, herido de Dios, y humillado.

En tercer lugar, aparece como pecador, como fruto del pecado y como lleno de pecados; por eso le dieron sepultura con los malvados y con los malhechores; fue contado entre los pecadores porque él cargó con el pecado de muchos.

En cuarto lugar, la visión creyente ve las cosas de otro modo: su estado no se debe a sus pecados, sufre el pecado sin haberlo cometido; fue traspasado por nuestras rebeliones y triturado por 
nuestros crímenes, herido por los pecados del pueblo. Cargó con los pecados que no cometio, de modo que está en situación desesperada por los pecados de los demás. Antes que el muera por los pecados, son los pecados lo que lo llevan a la muerte, son los que lo matan.

En quinto lugar, el siervo acepta este destino, acepta que el peso de los pecados lo lleve hasta la muerte, aunque él no los cometio. En razón de los pecados de los otros, por los pecados de los otros, acepta su propia muerte. El siervo justificará a muchos porque cargó con los crímenes de ellos. Nuestro castigo cayó sobre él y sus cicatrices nos curaron. Su muerte, lejos de ser sin sentido y sin eficacia, quita, por lo pronto, los pecados que afliglan al mundo. Es expiación e intercesion por los pecados.

En sexto lugar, el propio siervo, aplastado en su vida sacrificada y en su muerte fracasada, triunfando: no sólo los otros se verán justificados, sino que verá su descendencia y prolongará sus años; verá la luz y se saciará de conocimiento.

En séptimo lugar, el Señor mismo asume esta situación: carga sobre él todos nuestros crímenes. Más aún, se dice que el Señor quiso triturarlo con el sufrimiento y entregar su vida como expiación, aunque después lo premiará y dará la recompensa total. Son las frases más fuertes, pero que admiten la interpretación que Dios acepta como querido por El, como saludable, el sacrificio de quien históricamente es muerto por los pecados de los hombres. Sólo en un difícil acto de fe el cantor del siervo es capaz de descubrir lo que aparece como todo lo contrario a los ojos de la historia. Precisamente porque ve cargado de los pecados y de las consecuencias del pecado a quien no los cometió, se atreve, por la misma injusticia de la situación, a atribuir a Dios lo que está sucediendo; Dios no puede menos de atribuir un valor plenamente salvífico a este acto de absoluta injusticia histórica. Y se lo puede atribuir porque el propio siervo acepta su destino de salvar por el sufrimiento a quienes son los causantes de él.

Finalmente, la orientación global de este cántico, junto con la de los tres anteriores, su sentido profético de anuncio futuro y su ámbito de universalidad, hacen que no pueda determinarse univocamente la concreción histórica del siervo. Siervo doliente de Yahvé será todo aquel que desempeñe la misión descrita en los cánticos, y lo será por antonomasia quien la desempeñe de forma más total. Por mejor decir, siervo doliente de Yahvé será todo aquel crucificado injustamente por los pecados de los hombres, porque todos los crucificados forman una sola unidad, una sola realidad, 
aunque esta realidad tenga cabeza y tenga miembros con funciones distintas en la unidad de la expiación.

Por mucho que se acentúen los rasgos del sufrimiento y del aparente fracaso, sobresale la esperanza del triunfo, no lo olvidemos que ha de tener un carácter público e histórico y que se relaciona con la implentación del derecho y de la justicia. Todo lo que pueda haber de representación sustitutiva no obsta para que haya una efectividad histórica.

\subsection{Vida y muerte de Jeoús y Siervo de Yahvé}

Con anterioridad a la interpretación cristiana del siervo doliente ya se había puesto en relación su figura con la del Mesías. Una línea de reflexión teológica vio que el triunfo del Mesias no vendria sino después del paso por el dolor y el sufrimiento, y esto precisamente por la existencia del pecado. No puede desconocerse que el propio deutero-Isaías, que tanto subraya el amor de Yahvé por el pueblo, pone en su boca duras quejas sobre el mal comportamiento de ese pueblo. El misterio del pecado y del mal no deja abrirse camino hasta dar con una interpretación más cabal de la acción de Dios en la historia.

El Nuevo Testamento no recoge con profusión la referencia explícita al siervo de Yahvé. El título pais Theous aparece sólo una vez en Mateo $(12,15)$ y cuatro en $\operatorname{los}$ Hechos $(3,13-26 ; 4,27-30)$. Sin embargo, la teología del siervo doliente de Yahvé, en la línea del sufrimiento y la oblación por los pecados, es de primera importancia en el Nuevo Testamento cuando se pretende explicar teológicamente el hecho histórico de la muerte de Jesús. La desaparición casi completa del término puede atribuirse a que las comunidades helenísticas prefirieron muy pronto el título del "hijo de Dios" al de "siervo de Dios," que les resultaba un tanto inasimilable. Para J. Jeremias, la interpretación cristológica del siervo de Yahvé del deutero-Isaías pertenece a los primeros tiempos de las comunidades cristianas y corresponde al estadio palestino, prehelenístico. Cullmann sostiene que la cristologia del siervo es probablemente la cristología más antigua.

Sin embargo, no es opinión común de los exegetas que el propio Jesús tuviese conciencia de ser el siervo de Yahvé del que habla el deutero-Isaras. No necesitamos entrar aquí en discusión porque lo que nos importa subrayar es que la comunidad primitiva vio justificadamente el trasfondo teológico del siervo doliente en los sucesos históricos de la vida de Jesús, en cuyo caso éste, sin saberlo 
explícitamente, hubiera desempeñado la misión del siervo. Podría decirse, a modo de objeción, que los sucesos históricos narrados en los evangelios no son sino la carne histórica puesta por las comunidades primitivas para historizar el pensamiento teológico del siervo; pero aunque así fuera - lo cual no parece aceptable en su totalidad-, nos bastaria con el reconocimiento de la necesidad de historizar la salvación y el modo de salvación. Si, por otra parte, el propio Jesús tuvo conciencia de ser él la realización plena del siervo doliente de Yahvé, es claro que esta conciencia no la tuvo desde el principio de su vida, ni siquiera en los arranques de su vida pública; de lo cual se deduce de nuevo que sólo su vida real de anuncio del reino y de oposición a los enemigos del reino lo condujo a la aceptación creyente y esperanzada del destino salvifico del siervo: en El, la lucha contra el pecado habría sido también anterior a la muerte por el pecado.

Es, por lo pronto, difícil de admitir que Jesús haya manifestado pública $y$ solemnemente que su muerte fuera a tener un alcance salvifico (Schürmann). La predicación y el comportamiento de Jesús no se orientan hacia su muerte futura $y$ no dependen de ella (Marxsen). Más difícil resulta responder a la cuestión de si comunicó el sentido salvífico de su muerte a sus discípulos más cercanos, al menos en vísperas de la pasión, ya que no cuando fueron enviados a la misión de anunciar el reino. De hacerlo, tuvo que ser en la última cena. Sin poder entrar a fondo en esta cuestión, nos podemos atener a las posiciones intermedias de los exegetas, entre el positivismo literal de Jeremias y el escepticismo histórico de Bultmann. Schürmann, después de un largo análisis exegético, concluye: es una perspectiva soteriológica la que mejor explica los gestos de ofrenda de aquel que va a morir y que anuncia la salvación escatológica; en estos gestos del siervo realizados por Jesús, la salvación escatológica se hace comprensible en la acción simbolica de quien llega hasta el don de sí en la muerte como culminación de toda su vida, que ha sido siempre una pro-existencia, esto es, una vida definitiva por la entrega total a los demás. El reconocimiento del valor salvífico de la muerte de Jesús después de la resurrección quedó como posibilitado por el recuerdo de la actitud pre-existente de Jesús, expresada solemnemente en los gestos de la última cena y reconsiderada a la luz de las Escrituras, especialmente a la luz del siervo doliente. Se fue viendo que esa muerte era necesaria, que era conforme a las Escrituras, que tiene un valor salvífico para quienes lo siguieron y que ese valor puede extenderse a los pecados de la multitud.

Contra la autocompresión plena de su muerte por parte del propio 
Jesús está, sin embargo, su grito en la cruz recogido por Mateo (27, 26) y Marcos (15, 35), que parece indicar un absoluto abandono por parte de Dios y, consecuentemente, un desfallecimiento de su fe y de su esperanza. El texto presenta una dificultad tan grave, que los demás evangelistas lo sustituyen por una palabra de confianza (Lc $23,46-47$ ) o por una palabra de plenitud (Jn 19, 30). Siendo posible ver en las palabras de abandono de Jesús el comienzo del Salmo 22, que termina con palabras de esperanza semejante a los del cántico del siervo, no es seguro que éste sea el tenor ni el sentido de las palabras puestas en la boca de Jesús por Mateo y Marcos. Para León-Dufour, Jesús habría querido expresar el estado de derelicción, de abandono, que es la muerte, muerte que de por of es la separación del Dios vivo. Sin embargo, la experiencia del abandono es simultáneamente proclamada y negada en un dí́logo que expresa la presencia del que parece ausente; el dí́logo no queda interrumpido, aunque Dios parece haber desaparecido. Jesús, por vez única en los sinópticos, no llama a Yahvé "Padre", sino "Dios." Todo ello hace sospechar que el por qué me has abandonado queda sin respuesta inmediata que solamente aparecerá después de su muerte y que los evangelistas colocan en voz del centurion: "realmente, este hombre era el hijo de Dios."

Jesús, en consecuencia, no habría tenido conciencia explícita del sentido pleno de su muerte, aunque of la esperanza firme que su vida y su muerte eran el preanuncio inminente del reino; dicho en otras palabras, que el advenimiento definitivo del reino pasaba por su vida y por su muerte, entre las que ha de aceptarse una continuidad, de modo que la muerte no fue sino la culminación de su vida, el momento definitivo de su entrega total en el anuncio en la realización del reino. Hasta el punto que más claro estaría el sentido sacrificial y expiatorio de los sufrimientos del siervo doliente que el de la muerte de Jesús, sólo más tarde comprendida como víctima universal de los pecados del mundo.

\subsection{Para que el pueblo oprimido sea continuador de la re- dención de Jesús, el Siervo}

Obviamente, el pueblo crucificado no tiene conciencia explícita de ser el siervo doliente de Yahvé; pero, como acabamos de ver en el caso de Jesús, esto no es razón para negar que lo sea. Tampoco seria razón decir que Jesús mismo es el siervo doliente de Yahvé, pues el pueblo crucificado sería su continuidad histórica, de modo que no supondría "otro" siervo. Bastaria, por tanto, con mostrar que el pueblo crucificado reúne objetivamente algunas condiciones esenciales 
del siervo doliente para presumir que, gi no lo es actualmente y en toda su plenitud, es, sin embargo, el lugar histórico más adecuado de su realización.

Si se admite que la pasión de Jesús ha de tener continuación histórica, debe admitirse también, en razón de la historicidad, que esa continuación puede adoptar diversas figuras. Dejando de lado las figuras individuales, esto es, la necesidad de que Jesús prosiga en cada uno de sus seguidores, la continuación histórica por parte del pueblo deberá cobrar distintas figuras. Dicho en otros términos, no puede decirse de una vez por todas quién es el sujeto colectivo que lleva adelante con mayor plenitud la obra redentora de Jesús. Podría decirse que siempre será el pueblo de Dios crucificado; pero esto, siendo acertado, deja sin definir quién es ese pueblo de Dios, que no puede entenderse sin más como la Iglesia perseguida. No todo lo que se dice "Iglesia" es, sin más, el pueblo crucificado o el siervo doliente de Yahvé, aunque ese pueblo crucificado, rectamente entendido, pueda considerarse como la parte más viva de la Iglesia, precisamente porque continuaria la pasión y muerte de Jesús.

Esta historicidad no impide que pueda llegarse a una aproximación de la figura actual del siervo. Podrá ser distinta en diversas situaciones históricas, podrá representar según aspectos distintos sus rasgos fundamentales, pero no por ello podría dejar de tener ciertas características fundamentales. La más fundamental es que sea aceptado como tal por Dios; pero esta aceptación no es comprobable sino sólo a través de su "semejanza" con lo que le ocurrió al Jesús crucificado de la historia. Según esto, deberá ser crucificado por los pecados del mundo, deberá haber sido convertido en desecho de los hombres mundanos, su apariencia no será humana precisamente porque ha sido deshumanizada; deberá tener un alto grado de universalidad, pues se ha de tratar de una figura redentora del mundo entero; deberá sufrir esta deshumanización total no por sus culpas, sino por cargar con las culpas de los demás; deberá ser desechado y despreciado precisamente como salvador del mundo, de tal forma que este "mundo" no lo acepte como su salvador, antes al contrario, lo juzgue como la expresión más cabal de lo que se debe evitar y aun condenar; deberá, finalmente, darse una conexión objetiva entre su pasión y la realización del reino de Dios.

Por otra parte, no deberá identificarse esta figura histórica del siervo con una determinada organización del pueblo crucificado cuya instancia definitoria sea el alcance del poder político. Desde luego que la salvación prometida a la misión histórica del siervo de Yahvé 
ha de conseguir una objetivación y que esta objetivación histórica ha de ser lograda mediante una organización, la cual, si ha de ser plenamente liberadora, ha de estar en intima conexión con lo que es el pueblo crucificado. Pero no es el mismo aspecto aquel por el que el pueblo crucificado -y no un pueblo indiferenciado sin más- aporta la salvación al mundo, como continuador de la obra de Jesús, y aquel otro por el cual realiza histórico-políticamente esa salvación. Dicho de otra forma, el pueblo crucificado desborda cualquier concrecion histórica que pueda darse a sí mismo en vistas a su salvación histórica, y ese desbordamiento proviene de ser continuación histórica de un Jesús que no llevó su lucha por el reino a través del poder político; pero el hecho de que "desborde" no supone que se pueda apartar de toda concreción histórica, porque el reino de Dios implica la realización de un orden político en el cual los hombres vivan en alianza como la respuesta a la alianza de Dios.

El pueblo crucificado mantiene así una cierta indeterminación, en cuanto no se identifica, al menos formalmente, con un grupo histórico preciso -al menos con todas las concreciones de un grupo histórico-; pero, por otro lado, es suficientemente determinado como para no ser confundido con lo que no puede representar el papel histórico del siervo doliente de Yahvé. Por poner ejemplos a dos niveles distintos: el primer mundo no está en esa línea y sí lo está el tercer mundo, no lo están las clases ricas y opresoras, y sí lo están las clases oprimidas; no lo están quienes están al servicio de la opresión, por mucho que sufran en este servicio, y sí lo están los que luchan por la justicia y la liberación. El tercer mundo, las clases oprimidas, los que luchan por la justicia, "en tanto que" son tercer mundo, clase oprimida y luchadores por la justicia, están en la línea del siervo doliente, por más que no todo lo que hacen lo hagan necesariamente en la línea del siervo. Más aún, como ya se apuntaba al principio de este trabajo, esos tres niveles necesitan desdoblarse - no podemos entrar aqui en el estudio de las formas de ese desdoblamiento- en factores estrictamente políticos y en factores que, siendo históricos no son formalmente políticos.

Esta aproximación del pueblo crucificado al siervo de Yahvé es todo menos gratuita. Si es posible ver en uno y otro rasgos comunes fundamentales, está, además, la identificación hecha por el mismo Jesús, $\longrightarrow$ vista así objetivamente por la comunidad cristiana primitiva- entre El y los que sufren. Desde luego, los que sufren por su nombre o por el reino, pero también los que sufren sin saber que su sufrimiento tiene que ver con el nombre de Jesús y el anuncio de su reino. Pero es Mateo 25, 31-46 donde se expresa la identificación 
de un modo más preciso; pasaje que, por cierto, antecede literalmente a un nuevo anuncio de la pasión (26, 1-2).

El pasaje tiene una estructura de pacto (Pikaza) en su doble expresión (soy su Dios, que está en los pequeños, y serán mi pueblo ai aman a los pequeños), con un pacto que está mediado a través de la justicia interhumana. Es el juicio del reino, el juicio universal y definitivo, que saca a la luz la verdad de Dios entre los hombres; eata verdad está en la identificación del Hijo del hombre, constituido en rey, con los hambrientos, con los sedientos, con los peregrinos, con los desnudos, con los enfermos y los presos. Hijo del hombre es el que sufre con los pequeños; y es este Hijo del hombre, en tanto que encarnado en el pueblo crucificado, el que se va a constituir en juez: el pueblo crucificado es ya juez, aunque no formule juicio teológico, en su propia existencia; y ese juicio es salvación, en cuanto descubra, por oposición, el pecado del mundo y en cuanto posibilita el rehacer lo que está mal hecho; en cuanto propone una exigencia nueva como camino ineludible para conseguir la salvación. Se trata, no lo olvidemos, de un juicio universal en el cual se da sentencia sobre todo el curso de la historia. Pikaza observa que Mateo 25, 3641 implica una visión dialéctica del Jesús histórico; por un lado, ha sido pobre y, por otro, es el que ayuda al pobre; observado esto después de la pascua, Jesús aparece como el Hijo del hombre que sufre en los perdidos de la tierra, pero es a la vez Señor dispuesto a ayudarlos.

El pueblo crucificado tiene asf una doble vertiente: es la victima del pecado del mundo y es también quien aportará la salvación al mundo. Pero este segundo aspecto no es el que aqui nos toca desarrollar, del "muerto por nuestros pecados y resucitado por nuestra justificación" paulino; este trabajo, al deternerse en la crucifixión, sólo presenta la primera etapa. Una etapa centrada sobre la resurrección del pueblo debería mostrar cómo el crucificado por los pecados del mundo puede aportar en su resurrección la salvación del mundo. No hay salvación por el mero hecho de la crucifixión y de la muerte: sólo un pueblo que vive, porque ha resucitado de la muerte que se le ha infligido, es el que puede salvar al mundo.

El mundo de la opresión no está dispuesto a tolerar esto. Como en el caso de Jesús, está decidido a desechar la piedra angular para la construcción de la historia, está decidido a construir la historia desde el poder y la dominación, es decir, desde la anulación permanente de la inmensa mayoría de la humanidad oprimida. La piedra que desecharon los constructores vino a ser la piedra angular, 
piedra de tropiezo y roca de escéndalo. Esa piedra fue Jesús, pero lo es también el pueblo que ahora es suyo, porque sufre el mismo destino historico: los que un tiempo "no eren pueblo" ahora son "pueblo de Dios," los que eran "mirados sin misericordia" ahora son "mirados con misericordia." En este pueblo están las piedras vivientes con los cuales se edificará la nueva casa, en la cual habitará el sacerdocio nuevo, que ofrecera las nuevas victimas a Dios por mediación de Jesucristo (cfr. 1Pe 2, 4-10). 